\title{
An Exceptional Case of Aortic Dissection Resulting Left Ventricular Dys- function Related to Dynamic Obstruction of Left Main Coronary Artery
}

\author{
Ibrahim Basarici*, Huseyin Yilmaz and Ibrahim Demir
}

Akdeniz University School of Medicine, Department of Cardiology, Antalya, Turkey

\begin{abstract}
Acute aortic dissections are uncommon but highly mortal emergencies. Atypical presentations can be missed and delayed diagnoses may diminish favourable impact of medical, interventional and surgical procedures. Hereby we describe a painless aortic dissection case presented with heart failure due to functional obstruction of left main coronary artery resulting left ventricular dysfunction by presumptive myocardial stunning.
\end{abstract}

Keywords: Aortic dissection, dynamic obstruction, atypical presentation, myocardial stunning, left main coronary artery.

\section{CASE REPORT}

A 61 year old women complaining for recently progressing dyspnea was referred to our clinic for suspected heart failure. She was healthy and free of cardiovascular risk factors until exertional dyspnea and palpitation occurred 2 weeks ago. Physical examination was completely normal. Electrocardiography showed an old anterior myocardial infarction pattern. Transthoracic echocardiography was performed which revealed moderate systolic dysfunction (left ventricle ejection fraction was $45 \%$ ) and hypokinesis in anterolateral segments. Valvular functions were normal except mild aortic insufficiency. Also in proximal ascending aorta a longitudinal echogenic structure was suspected as a dissection flap. Computed (spiral) tomography depicted a Stanford type-A / De Bakey type II aortic dissection (AD). Surgical consultant decided aortic surgery and demanded a preoperative cardiac catheterization to define concomitant coronary artery disease. Coronary angiography and aortagraphy was performed via standard Judkins technique. We determined a diminutive true lumen (Fig. 1) and a large false lumen which communicated just before the brachiocephalic trunk. Aortic root was distorted due to compression by false lumen. Right coronary artery take off was considerably anteriorly but it was free of stenosis. A dynamic compression was detected in the left main coronary artery (Fig. 2A, B) which resulted intermittent obstruction of the blood flow. After the cardiac catheterization a cerebrovascular ischemic attack presented by dysphasia occurred in the patient (cranial magnetic resonance imaging showed left temporoparietal acute infarction). This required deferring aortic surgery. After partial neurological improvement the patient was discharged on medical treatment including a beta blocker and angiotensin converting enzyme inhibitor. A phone contact was established 3 months later which revealed that the patient recovered neurologically but she refused aortic surgery. Attempts to communicate with the patient 6 and 9 months later were unsuccessful.

*Address correspondence to this author at the Akdeniz Üniversitesi Tip Fakultesi, Kardiyoloji Anabilim Dalı, 07059 Antalya, Turkey; Tel: 90 - 242 - 2496806 - 24967 75; Fax: 90 - 242 - 22744 90;

E-mail: ibasarici@akdeniz.edu.tr

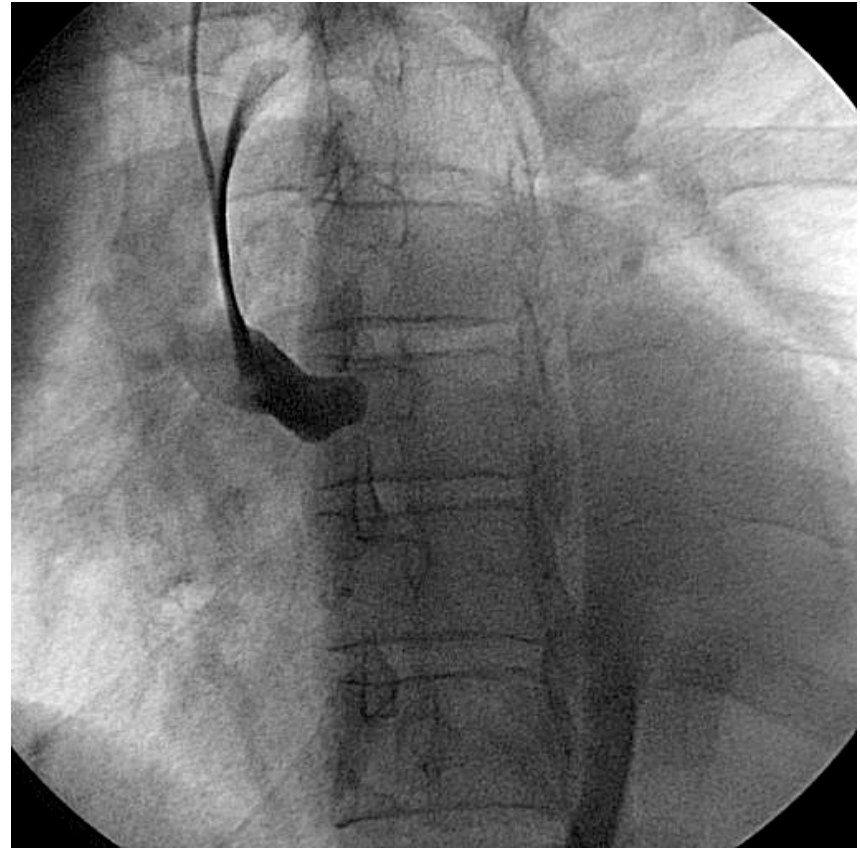

Fig. (1). Aortagraphy (in left oblique view) displays the diminutive true lumen (opacipied by the contrast media) besides a large false lumen (unvisible because it is not opacified).

\section{DISCUSSION}

Acute proximal $\mathrm{AD}$ is uncommon but a life threatening emergency which is typically characterized by sudden onset of tearing like anterior chest pain and generally accompanying hypertensive attack [1]. The culprit aortic intimal flap divides the aortic lumen into true and false lumens and the dissection flap may advance in either antegrade or retrograde directions [2]. Malperfusion symptoms of coronary arteries or aortic side-branches occur due to obliteration or compression by the extending false lumen. When coronary ostia are involved acute myocardial infarction may complicate the clinical course. At least one coronary artery ostium -preferentially the right coronary artery- is involved in about $11 \%$ of type-A AD [3]. The mechanism may be the progression of intimal tear into the coronaries in retrograde way or there may be a dynamic or static compression of the coronary artery ostium by 
dissection flap or intramural hematoma. In patients with coronary involvement the mortality of acute AD is high and when diagnosis is missed or if thrombolytic therapy is applied erroneously the result may be catastrophic [4]. However transesophageal echocardiography, conventional angiography or multi-detector computed tomography can help determining coronary involvement [5-9] in suspected cases. In such cases where acute myocardial infarction due to coronary involvement accompanies acute AD, successful reperfusion by percutaneous coronary intervention is possible and may serve as a safe bridge to surgery $[6,10]$.

(A)

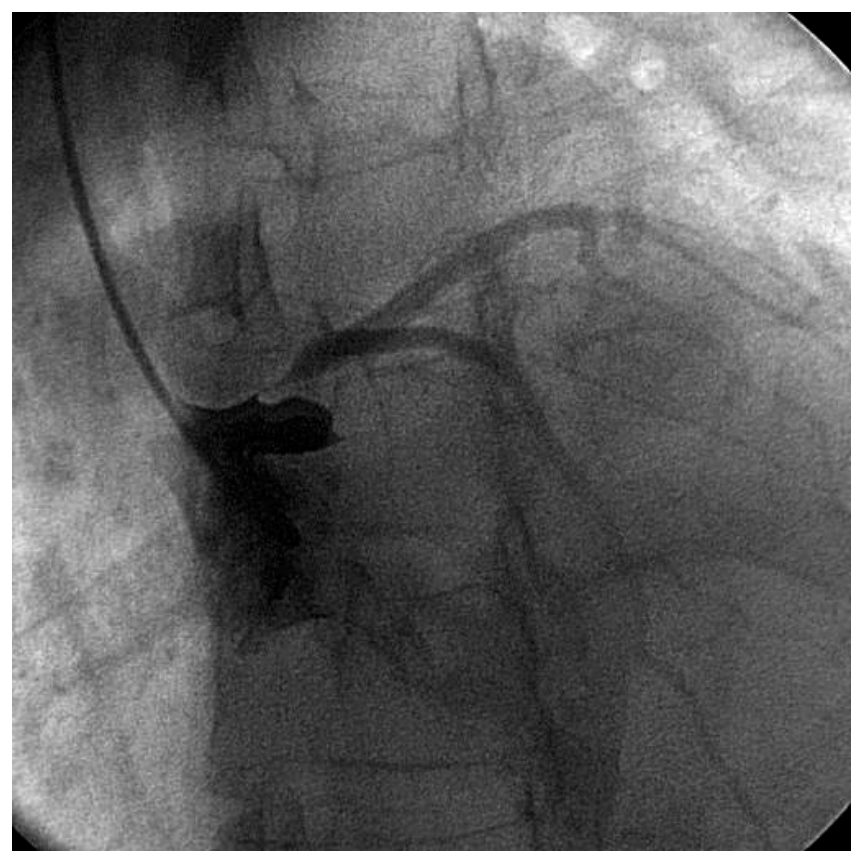

(B)

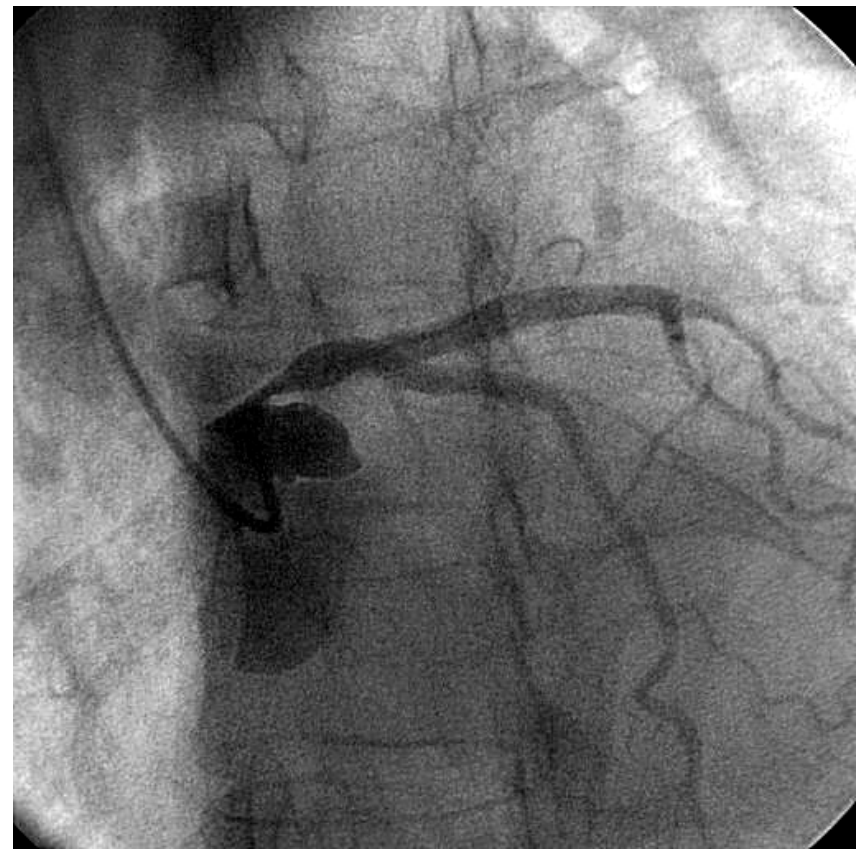

Fig. (2). Coronary angiography (in anteroposterior cranial view) shows (A) intermittent obstruction of blood flow in left main trunk in systole and (B) a partial relief in diastole.
It is important to underline that painless AD present with a reported incidence of 6.4-8.3\% [1,11]. These cases are more prone to be present with heart failure or neurological signs such as syncope, stroke or transient global amnesia [11-13] and are associated with higher mortality rates especially when it is related to a type-B AD [11].

The above described case represents most atypical features of aortic dissections. The presentation was not an acute setting. The patient was painless (which unables us to estimate beginning of the acute phase exactly) and the main symptom was progressive dyspnea. The diagnosis was established upon accidental findings on echocardiography performed to investigate heart failure. Cardiac failure sometimes may be the prominent symptom in AD but usually it follows a period of pain and generally is associated with severe aortic insufficiency [14]. These traits were absent in this case. But despite overt dyspnea at rest and depressed left ventricular function on echocardiography there was not any clinical finding related to heart failure. So we should note the possibility of angina equivalent dyspnea in this case. Moreover electrocardiography indicated an old anterior myocardial infarction which evolved without any chest pain history. Therefore the heart failure symptoms could partly be attributed to moderate left ventricular dysfunction related to old myocardial infarction in this patient. Eventually coronary angiography was performed to determine concomitant coronary artery disease. Cardiac catheterization revealed that the myocardial infarction was not associated with obliterative coronary artery disease or involvement of coronary ostium, but it was related to dynamic compression of left main coronary artery which is also uncommon. Possibility of catheter induced spasm is questionable at this point. But it is already eliminated by avoiding selective engagement to left main coronary artery and performing a nonselective angiography via pigtail located at the aortic root. We propose that left ventricular dysfunction may be related to myocardial stunning rather than an infarction. Documentation of reversibility of wall motion abnormality in anterolateral segments by stress echocardiography could help addressing the precise diagnosis. Also this could justify the operation indication and convincing the patient to undergo surgery. However considering some handicaps in this case (concerning the risks of test requirements; such as discontinuation of beta blocker therapy and use of inotropic agent in an AD case) stress echocardiography was not performed, so we could not prove our hypothesis about myocardial stunning. Also medical treatment and surgical intervention can correct ischemic electrocardiography changes when left main coronary artery obstruction is functional $[8,9]$. As no intervention was performed to eliminate functional obstruction it was impossible to see if these electrocardiographic and echocardiographic changes were temporary. Finally it is proposed that the clinical course of unrecognized or late diagnosed AD cases resemble the natural unfavourable course of acute AD [1]. Atypical presentations come in to prominence in this context because they may be easily overlooked by physicians and the diagnosis may prolong. Coronary involvement in $\mathrm{AD}$ is a well known entity. The dynamic obstruction reported in this paper is an exceptional type of involvement. Presence and pattern of coronary involvement further complicates the course of aortic dissections. It may yield an accompanying acute myocardial infarction which can require combined/ 
consecutive percutaneous and surgical interventions $[6,10]$. Even if it does not result an acute myocardial infarction as in above reported case, coronary involvement becomes a diagnostic dilemma in terms of documentation. Conventional aortagraphy and coronary angiography may expose these susceptible patients to potential hazards of intervention. Therefore we should prefer to utilize "non-invasive" procedures (whereas available) in current practice (rather than "conventional old gold standards") to minimize these risks. Because novel diagnostic tools such as multi-dimensional computed tomography [14] offer reliable and complementary results (But it was unavailable for our case because of a technical problem at that time). Eventually the clinical course in our patient was unexpectedly favourable despite deferral of aortic surgery when cardiac catheterization was complicated by a cerebrovascular event. But it should be emphasized that this commend covers only the short term follow-up and failed long term communication attempts does not warrant survival in follow-up.

\section{CONCLUSIONS}

Acute $\mathrm{AD}$ has a malignant clinical course especially when accompanied by myocardial infarction due to coronary involvement. Dynamic obstruction of left main coronary artery is one of the possible and rare manifestations of coronary involvement patterns and may yield left ventricular dysfunction or heart failure. "Possibility of atypical presentations should be kept in mind" to suspect and diagnose AD to provide reductions in mortality by prompt appropriate treatments.

\section{REFERENCES}

[1] Meszaros I, Morocz J, Szlavi J, et al. Epidemiology and clinicopathology of aortic dissection: A population based longitudinal study over 27 years. Chest 2000; 117: 1271-8.
[2] Nienaber CA, Haverich A, Erbel R. Diseases of the Aorta and Trauma to the Aorta and the Heart. In: Camm JA, Lüscher TF, Serruys PW, Eds. The ESC Textbook of Cardiovascular Medicine, $1^{\text {st }}$ ed. Oxford: Blackwell Publishing 2006; pp. 993-1031.

[3] Neri E, Toscano T, Papalia U, et al. Proximal aortic dissection with coronary malperfusion: Presentation, management and outcome. J Thorac Cardiovasc Surg 2001; 121: 151-60.

[4] Eriksen UH, Mølgaard H, Ingerslev J, Nielsen TT. Fatal haemostatic complications due to thrombolytic therapy in patients falsely diagnosed as acute myocardial infarction. Eur Heart J 1992; 13(6): 840-3.

[5] Vianna CB, Puig LB, Vieira ML, Shiozaki AA, Dauar D, Cesar LA. Spontaneous aortic dissection limited to sinus of valsalva and involving the left main coronary artery. Int J Cardiovasc Imaging 2007; 23(4): 455-8.

[6] Cardozo C, Riadh R, Mazen M. Acute myocardial infarction due to left main compression aortic dissection treated by direct stenting. J Invasive Cardiol 2004; 16(2): 89-91.

[7] Feuchtner GM, Schachner T, Friedrich G, Antretter H, Bonatti J, zur Nedden D. Acute aortic dissection with coronary ostium involvement and aortic valve regurgitation: Three dimensional visualization with multislice computed tomography. J Thorac Cardiovasc Surg 2005; 130(2): 587-8.

[8] Kazuhiro A, Arakawa K, Yamagishi T, et al. A case of aortic dissection with transient ST-segment elevation due to functional left main coronary artery obstruction. Jpn Circ J 2000; 64: 130-4.

[9] Shapira OM, Davidoff R. Functional left main coronary artery obstruction due to aortic dissection. Circulation 1998; 98: 278-80.

[10] Barabas M, Gosselin G, Crépeau J, Petitclerc R, Cartier R, Théroux $P$. Left main stenting-as a bridge to surgery-for acute type A aortic dissection and anterior myocardial infarction. Catheter Cardiovasc Interven 2000; 51(1): 74-7.

[11] Park SW, Hutchison S, Mehta RH, et al. Association of painless acute aortic dissection with increased mortality. Mayo Clin Proc 2004; 79(10): 1252-7.

[12] Ayrik C, Cece H, Aslan O, Karcioglu O, Yilmaz E. Seeing the invisible: painless aortic dissection in the emergency setting. Emerg Med J 2006; 23(3): e24.

[13] Mondon K, Blechet C, Gochard A, et al. Transient global amnesia caused by painless aortic dissection. Emerg Med J 2007; 24: 63-66.

[14] Erbel R, Alfonso F, Boileau C, et al. Task Force Report: Diagnosis and management of aortic dissection. Recommendations of the Task Force on Aortic Dissection, European Society of Cardiology. Eur Heart J 2001; 22: 1642-81.

(C) Basarici et al.; Licensee Bentham Open.

This is an open access article licensed under the terms of the Creative Commons Attribution Non-Commercial License (http://creativecommons.org/licenses/by$\mathrm{nc} / 3.0 /$ ) which permits unrestricted, non-commercial use, distribution and reproduction in any medium, provided the work is properly cited. 